\title{
Clinical characteristics of lower extremity ulcers
}

Common causes of lower-extremity ulcers are relatively easy to diagnose, but exact wound diagnosis needs always a holistic approach and a careful evaluation of the wound patient. Systematic assessment and the use of check-lists provides diagnostic tools. This review aims to provide clinicians with an overview of the different aetiologies of leg ulcer by describing the clinical characteristics of each aetiology. It also aims to provide tools for health-care providers when assessing a lower-extremity ulcer patient.

\author{
Keywords: \\ venous leg ulcers; arterial ulcers; mixed arterial and venous leg ulcers; pressure ulcers; \\ diabetic foot ulcers; atypical wounds
}

\begin{abstract}
Background

Exact diagnosis of lower-extremity ulcers is essential for successful ulcer management, and it often needs a multidisciplinary approach. The most common aetiologies for lower-extremity leg ulcers are venous, arterial, mixed venous and arterial, diabetic and pressure ulcers. However, atypical wounds comprise approximately $20 \%$ of chronic wounds and should be kept in mind during differential diagnosis.

Aim

This review aims to provide clinicians with an overview of the different aetiologies of leg ulcer by describing the clinical characteristics of each aetiology. It also aims to provide tools for health-care providers when assessing a lower-extremity ulcer patient.
\end{abstract}

\section{Findings}

Ulcers with more than one aetiology are not uncommon. This awareness is increasing, and a holistic, systematic and checklist-based assessment is strongly recommended for each wound patient. One diagnosis does not exclude another. Diagnostic delay is especially common in atypical wounds. If the wound does not heal with good standard treatment, the diagnosis should be evaluated again.

\section{Conclusion}

The literature indicates that while precise wound diagnosis may be easy in theory, it is not always so in practice. Successful wound management implies good collaboration between physicians and tissue viability nurses, and with complicated patient cases, a multidisciplinary approach is mandatory. There is a need for reliable epidemiological research, using clear criteria for wound diagnosis, to estimate the prevalence and incidence of these wounds and also their impact on health, economics and quality of life.

Implications for clinical practice Checklists should be incorporated into clinical prac-

\footnotetext{
1. Specialist in Dermatology and Allergology, Helsinki University Central Hospital and Helsinki University, Helsinki Wound Healing Centre

2. Specialist in Vascular Surgery, Helsinki University Central Hospital and Helsinki University, Helsinki Wound Healing Centre

3. Advanced Nurse Practitioner Plastic Surgery, Beaumont Hospital and Royal College of Surgeons in Ireland (RCSI)

4. Specialist in Plastic Surgery, Helsinki University Central Hospital and Helsinki University, Helsinki Wound Healing Centre 
tice in wound clinics, and wound diagnosis should be re-analysed at every control point. Negative treatment response should always raise the question whether wound diagnosis is correct.

\section{Key message}

Determining exact wound aetiology is crucial for successful wound management, and checklists should be incorporated into clinical practice. Clinicians are challenged by the fact that the number of multiaetiological ulcers is increasing, and a multidisciplinary approach is often necessary.

\section{INTRODUCTION}

A lower-extremity ulcer can be defined as an open lesion on the lower limb due to full thickness skin loss, resulting in chronic wound progression. It is estimated that the prevalence of lower-extremity ulcers is from 1,5 to $2 \%$ of the adult population. ${ }^{1,2}$ This figure is probably underestimated as many studies incorporate only venous leg ulcers. Indeed, a recent study from Wales revealed a prevalence of $6 \%$ for chronic wounds at the population level. ${ }^{3}$ Lower-extremity ulcers cause substantial annual costs and reduced health-related quality of life for the patients so affected. ${ }^{2,4,5}$ Even if lower-extremity ulcers are more common in elderly people, it has been estimated that $22 \%$ of individuals with a leg ulcer have developed their first venous leg ulcers by 40 years of age and $13 \%$ before 30 years of age, thus affecting their ability to work and participate in social activities. ${ }^{6}$ As lower-extremity ulcers are a symptom of disease, the most important step in achieving successful wound healing is to determine the exact wound aetiology. 7,8 However, misdiagnosis due to a lack of systematic assessment of wound patients occurs frequently among health-care providers. ${ }^{9}$ Multi-aetiological wounds are wounds that have at least two aetiologies, such as arterial and venous, and the increasing number of these multi-aetiological ulcers is a challenge to clinicians. ${ }^{10}$ In general, the diagnostic process is the physician`s responsibility. However, nurses play an important role as they usually monitor the wounds and the patients for longer, and they are therefore in a position to recognise and respond to delayed healing within a reasonable time frame. In many cases, successful diagnosis requires a multidisciplinary approach. This review intends to give a comprehensive list of the different aetiologies and to suggest tools for healthcare providers when assessing a lower-extremity ulcer patient.

\section{Different aetiologies for lower-extremity ulcers}

The most common aetiologies for lower-extremity ulcers are venous leg ulcers, diabetic foot ulcers, pres-

Table 1.

Major aetiologies for lower-extremity ulcers and recommended diagnostic procedures

The major etiologies for lower-extremity ulcers

\begin{tabular}{ll}
\hline Venous leg ulcers & Duplex ultrasonography \\
\hline Arterial ulcers & $\begin{array}{l}\text { Pulse palpation, ankle brachial pressure index, } \\
\text { toe pressure, toe brachial index, angiography }\end{array}$ \\
\hline Mixed arterial and venous ulcers & $\begin{array}{l}\text { Combined diagnostics of venous and arterial } \\
\text { ulcers (see above) }\end{array}$ \\
\hline Diabetic foot ulcers & $\begin{array}{l}\text { Glucose profile, monofilament test, pulse } \\
\text { palpation, toe brachial index, angiography }\end{array}$ \\
\hline Pressure ulcers & $\begin{array}{l}\text { Clinical characteristics, monofilament test } \\
\text { Atypical ulcers }\end{array}$ \\
$\begin{array}{l}\text { Biopsy but also clinical evaluation, negative } \\
\text { histology does not exclude an atypical cause } \\
\text { of the ulcer }\end{array}$ \\
\hline
\end{tabular}


Table 2.

Atypical causes of ulcers

Atypical ulcer

\begin{tabular}{|c|c|}
\hline Vasculitis & $\begin{array}{l}\text { Related to rheumatoid arthritis and } \\
\text { connective tissue diseases }\end{array}$ \\
\hline Pyoderma gangrenosum & $\begin{array}{l}\text { Related to inflammatory bowel disease, } \\
\text { rheumatoid arthritis and hematologic } \\
\text { malignancies }\end{array}$ \\
\hline Martorell hypertensive ulcer & $\begin{array}{l}\text { Related to hypertension, type II diabetes } \\
\text { and warfarin medication }\end{array}$ \\
\hline Calciphylaxis & Related to uremic disease \\
\hline Malignant wounds & Related to age and immunosuppression \\
\hline Occlusive vasculopathies & e.g. livedoid vasculopathy \\
\hline Ecthyma gangrenosum & Related to immunosuppression \\
\hline Artefactal ulcers & Related to personality disorders \\
\hline Medication-related & e.g. hydroxyurea, methotrexate \\
\hline \multicolumn{2}{|l|}{ Sickle cell disease } \\
\hline Infectious & e.g. leishmaniasis, tuberculosis \\
\hline
\end{tabular}

sure ulcers, arterial ulcers and mixed venous arterial ulcers (Table 1). ${ }^{9,11}$ It is important to keep in mind that some ulcers may initially occur traumatically, but the healing process may become stalled due to an underlying pathological disease. Therefore, a patient with a traumatic ulcer on the lower extremities should be assessed carefully in order to exclude diseases that would affect acute wound healing. One diagnosis does not exclude another, for example, up to $25 \%$ of patients with a venous leg ulcer have concomitant peripheral arterial disease. ${ }^{10}$ If the wound does not fall into a typical category, has an abnormal location or clinical appearance or does not show healing within three months, an atypical cause should be suspected (Table 2). ${ }^{9,11,12}$

\section{Physical examination of a} lower-extremity ulcer patient

Patients should be examined holistically as a careful history will provide clues for the diagnosis (Table 3). The use of a standardized checklist is strongly recommended. ${ }^{13}$ The arterial system should be assessed in every patient, including pulse palpation and measurement of the ankle brachial index. This is also mandatory before the use of compression therapy. The American Diabetes Association has determined that an ankle brachial pressure index (ABPI) of between $0.91-1$, is within the normal range, mild peripheral arterial disease is defined as an ABPI of 0.7-0.9, moderate ischemic disease as $0.41-0.69$ and critical limb ischemia as $\leq 0.4{ }^{14,15}$ However, ABPI is not reliable in patients with diabetes or in elderly patients. If the pulses are not palpable in diabetic patients or if the suspicion of ischaemia is high in elderly patients, a prompt referral should be made to a specialist for measurement of toe brachial index (TBI) and toe pressure (TP) and for accurate interpretation of the results. 
Table 3.

Patient history and its relevance to lower extremity ulcers

Patient history

\begin{tabular}{|c|c|}
\hline Primary varicosis or venous thrombosis & Venous leg ulcer \\
\hline $\begin{array}{l}\text { Coronary heart disease, cerebrovascular } \\
\text { infarction, smoking }\end{array}$ & Arterial ulcer \\
\hline Diabetes & $\begin{array}{l}\text { Diabetic foot ulcer, necrobiosis lipoidica, } \\
\text { calciphylaxis }\end{array}$ \\
\hline Rheumatoid arthritis, connective tissue diasease & Vasculitic ulcers, pyoderma gangrenosum \\
\hline Inflammatory bowel disease & Pyoderma gangrenosum \\
\hline Hematologic malignancies & Pyoderma gangrenosum \\
\hline Uremic disease & Calciphylaxis \\
\hline Medication: hydroxyurea, warfarin & $\begin{array}{l}\text { Hydroxyurea-ulcers, warfarin necrosis, } \\
\text { Martorell hypertensive ulcers, calciphylaxis }\end{array}$ \\
\hline Travel history, immunosuppression & $\begin{array}{l}\text { Leishmaniasis, tuberculosis, malignant } \\
\text { ulcers, ecthyma gangrenosum }\end{array}$ \\
\hline Psychological factors, personality disorders & Patient concordance, artefactal ulcers \\
\hline Obesity & Venous leg ulcers, calciphylaxis \\
\hline
\end{tabular}

Potential diagnosis 


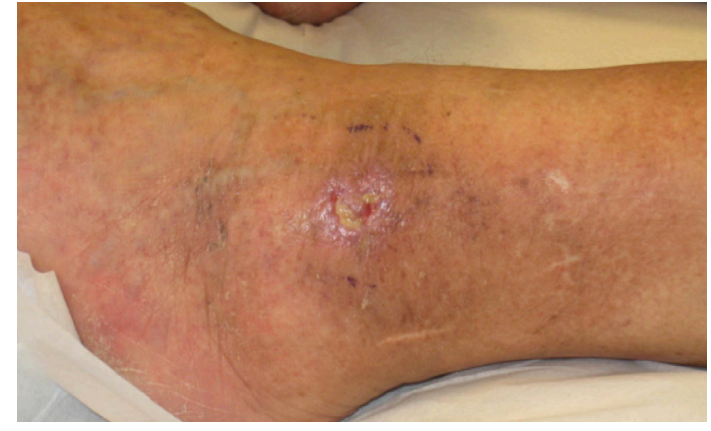

Figure 1. A venous leg ulcer in a 71 year old man in the lateral malleolar region.

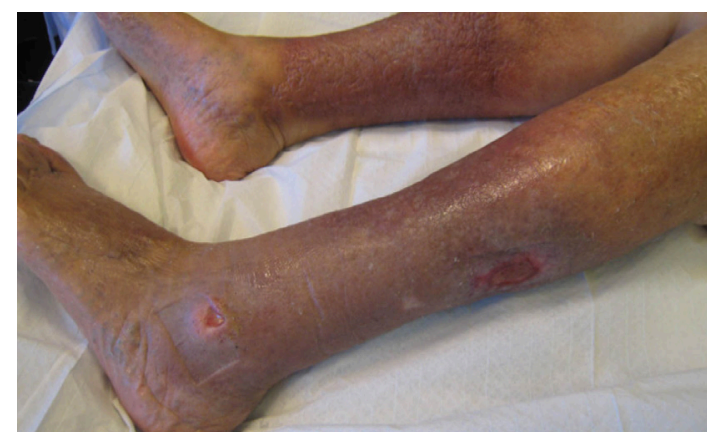

Figure 3. Mixed venous and arterial ulcers in a 84 years old man.

Venous leg ulcers are usually moderately to highly exudating and contain fibrinous slough, but bacterial infection is uncommon. Therefore, in the absence of clinical signs of infection, bacterial swabs are not routinely recommended. ${ }^{1}$

\section{Arterial ulcers}

Peripheral arterial disease should always be the first exclusion diagnosis in all lower-extremity ulcers, together with severe infection. Frequent comorbidities include diabetes, coronary heart disease and cerebrovascular disease. ${ }^{1}$ Smoking is a major risk factor. Arterial ulcers comprise about $15-20 \%$ of all leg ulcers. They are typically deeper, drier and more necrotic than venous leg ulcers (Figure 2). Toes, feet and heels are the most frequent locations, but any other location is possible. ${ }^{9}$ Prompt diagnosis of an arterial ulcer is important in order to avoid amputation.

\section{Mixed venous arterial leg ulcers}

Mixed arterial venous disease is estimated to affect up to $26 \%$ of patients with lower extremity ulcerations, however their pathophysiology is not well studied. ${ }^{22}$ Mixed venous arterial ulcers usually combine the clinical characteristics of venous leg ulcers and arterial ulcers. They are located in the medial or lateral aspects of the leg, and circumferential extension is

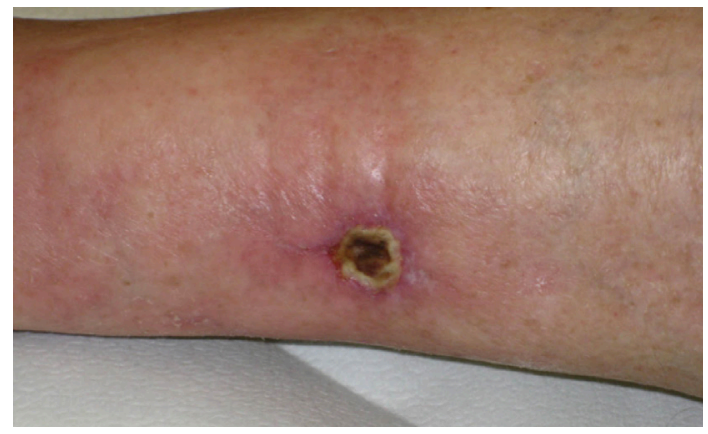

Figure 2. An arterial ulcer in a 69 years old woman in the left calf.

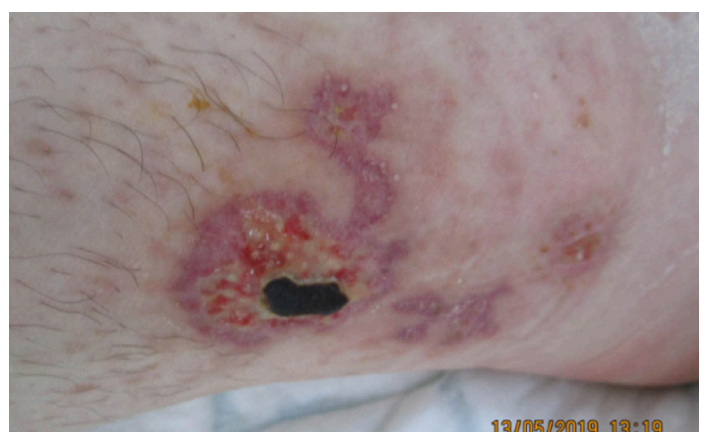

Figure 4. A vasculitic ulcer in the ankle region of a 22 year old man.

not uncommon (Figure 3). In these cases, the clinical suspicion is important and a thorough arterial and venous evaluation should be performed. ${ }^{22}$

\section{Diabetic foot ulcers}

Diabetic foot ulcers are the most common foot ulcers, and the lifetime risk of a diabetic patient developing a foot ulcer is approximately $25 \% .^{23}$ For this reason, the glucose profile of a patient with a foot ulcer should always be evaluated. The pathophysiology of diabetic foot ulcers includes peripheral neuropathy and peripheral arterial disease. Approximately 50\% of diabetic foot ulcers occur in the toes or web spaces. The other $50 \%$ of ulcers are plantar in the forefoot, midfoot or heel. ${ }^{24}$ In addition, the peri-wound skin often contains hyperkeratotic skin called callus, and this is a typical sign of a diabetic neuropathic ulcer. ${ }^{25}$ In diabetic foot ulcer patients it is important to consider whether the patient is in need of urgent hospital admission for an ischaemic or infected diabetic foot.

\section{Pressure ulcers}

Pressure ulcers develop most commonly on bony prominences as a result of pressure or pressure in combination with shear stress. ${ }^{26}$ Typical locations of pressure ulcers in the lower-extremities are the heels, the malleolar region and the toes. Risk factors include 


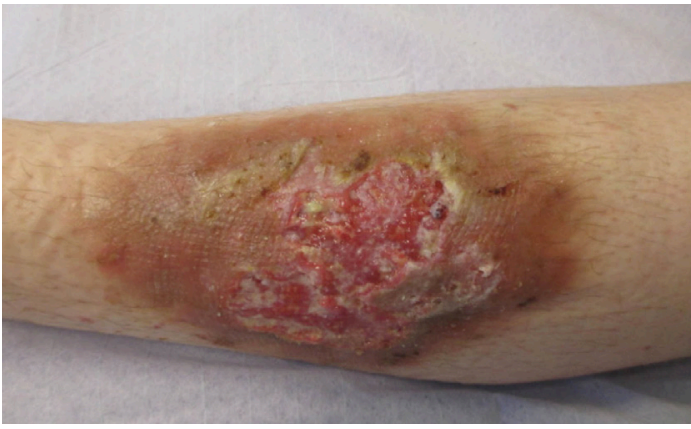

Figure 5. A Pyoderma gangrenosum ulcer in a 26 years old woman.

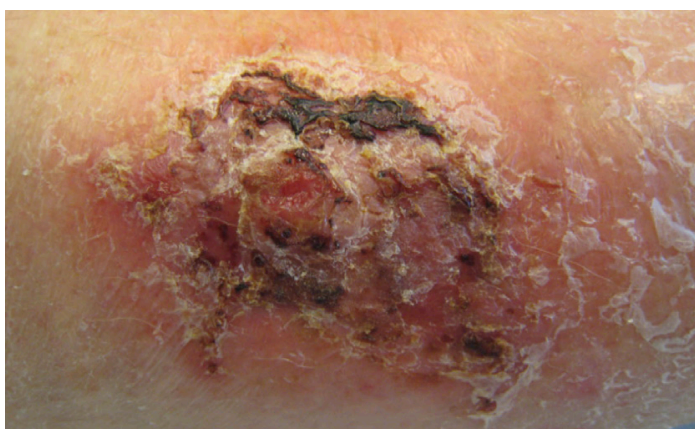

Figure 7. An eczematized basalioma in a 77 years old man.

peripheral arterial disease, limited mobility, diabetes, rheumatoid arthritis and forefoot deformity. 8,9,26,27

\section{Atypical causes of leg ulcers}

The prevalence of atypical ulcers (Table 2) has previously been underestimated, but a recent document estimates that they comprise up to $20 \%$ of all chronic wounds. ${ }^{11}$ Many of them probably remain undiagnosed, and it is important that every health-care professional treating chronic wounds is aware of this possibility and recognizes when to refer the patient on to a specialist (e.g. a dermatologist). Recognizing atypical ulcers is also important because many of them are worsened by debridement or surgical revision before starting with, for example, immunosuppressive therapy. ${ }^{11}$

Vasculitic ulcers occur due to an inflammatory process, which leads to the destruction of the walls of blood vessels. The ulcers result from ischaemic necrosis of the vessels. ${ }^{11}$ Cutaneous vasculitis, occurring as vasculitic ulcers, can be classified as: i) a cutaneous component of a systemic vasculitis (e.g. cutaneous manifestations of polyarteritis nodosa; PAN), ii) a skin-limited or skin-dominant expression or variant

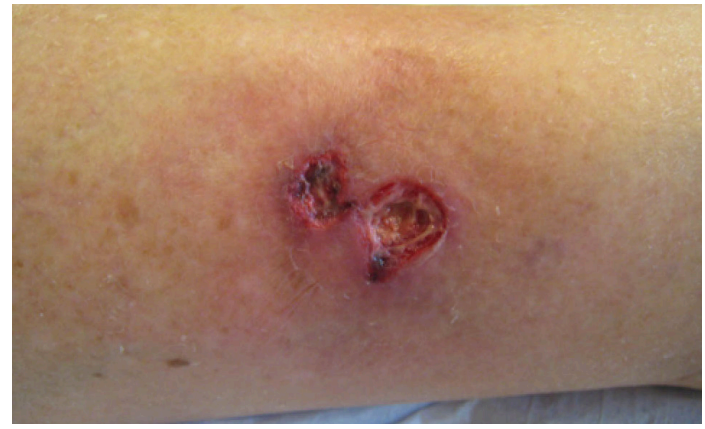

Figure 6. A Martorell ulcer in the right leg of a 70 years old woman who had diabetes and hypertension.

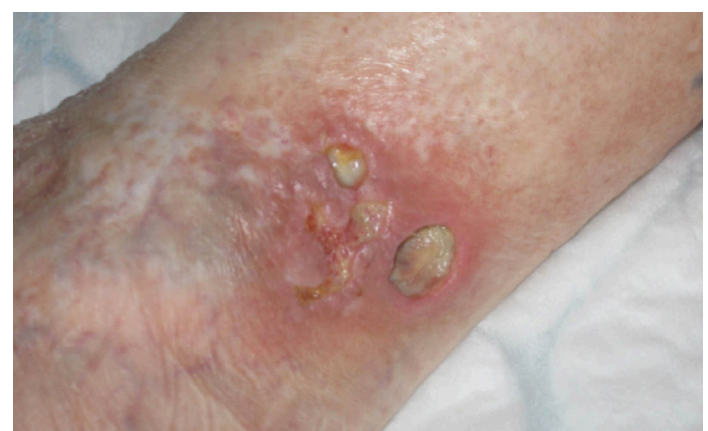

Figure 8. Livedoid vasculopathy ulcers in the ankle region a 50 years old woman (notice atrophie blanche around the ulcers)

of a systemic vasculitis (e.g. cutaneous PAN or cutaneous arteritis), or iii) a single organ vasculitis (SOV) of the skin. ${ }^{28}$ The clinical picture of cutaneous vasculitis includes palpable and retiform purpura, livedo racemosa and necrotic ulcers (Figure 4).

Pyoderma gangrenosum (PG) is a neutrophilic disease of the skin, and it is associated with inflammatory bowel disease, rheumatoid arthritis and hematologic malignancies. ${ }^{11}$ A PG lesion starts typically as a pustule and rapidly evolves into a painful ulcer with superficial necrosis and violaceous borders (Figure 5). It is important not to debride these ulcers before starting with immunosuppressive therapy as they exhibit the pathergy phenomenon whereby they are exacerbated by trauma. ${ }^{11}$ PG can also occur after surgery, especially after breast surgery. ${ }^{29,30}$

Martorell hypertensive ulcers and calciphylaxis are both diseases that share common pathophysiology: subcutaneous arteriolosclerosis. ${ }^{31}$ Martorell hypertensive ischaemic leg ulcer is associated with type II diabetes, hypertension and vitamin $\mathrm{K}$ antagonists, and the typical location is the laterodorsal leg and the Achilles tendon. ${ }^{11,31}$ The ulcers are painful, rapidly 
growing and often have a narrow red band around the wound borders (Figure 6). Calciphylaxis is associated with chronic renal insufficiency and obesity and is divided into distal and proximal patterns. ${ }^{11}$ Both Martorell hypertensive ulcers and calciphylaxis can be lethal. ${ }^{31,32}$

Malignant wounds are increasing with an aging population, and in a prospective multicentre study in which all included patients with non-healing chronic leg ulcers were biopsied, malignant wounds showed a prevalence of as high as $10.4 \% .{ }^{33}$ The diagnosis can be substantially delayed as a malignant wound can look like a chronic leg ulcer of any other cause. Signs of a malignant wound include atypical ulcer location, hypergranulation, irregular wound borders, wound odour, increased wound pain and bleeding of the wound (Figure 7). ${ }^{11,33}$ Any leg ulcer that does not show sufficient healing tendency in the course of 4-12 weeks should be biopsied in order to exclude malignancy. ${ }^{11}$

Occlusive vasculopathy may be defined as a blood vessel disorder mainly characterised by a diminishment or even complete occlusion of the vessel lumina, and occlusive vasculopathies can be divided into three major groups: embolization, intravascular thrombi and coagulopathies. ${ }^{11}$ One form of coagulopathy is livedoid vasculopathy, which presents as recurrent, painful ulcers around the ankles and typically, affects middle-aged women (Figure 8). The pathophysiology of ulcers in sickle cell disease is not well known, but vasculopathy probably plays a major role. ${ }^{34}$
Artefactal ulcers are associated with personality disorders and display geometric or other unusual patterns, with sharply demarcated edges and they spare anatomic areas that are difficult to reach. ${ }^{11}$ Artefactal ulcer is a diagnosis of exclusion. ${ }^{11,35}$

Ecthyma gangrenosum is a cutaneous manifestation of bacterial infection, especially of Pseudomonas aeruginosa. It affects especially immunocompromised patients and presents with erythematous or purpuric macules that rapidly evolve into vesicles or nodules and subsequently into ulcers with a black eschar formation and a surrounding erythematous halo. ${ }^{11}$

Medications such as hydroxyurea, methotrexate and nicorandil can also cause lower-extremity ulcers. Leishmaniasis, tuberculosis and other infections, as well as a variety of dermatological conditions are also causes of atypical wounds. ${ }^{11,12}$

\section{CONCLUSION}

Common causes of lower-extremity ulcers are relatively easy to diagnose, but exact wound diagnosis needs always a holistic approach and a careful evaluation of the wound patient. Systematic assessment and the use of check-lists provides diagnostic tools, for example, for multiaetiological wounds, as one aetiology does not exclude another. In addition, tissue viability nurses play a crucial role as they can usually monitor lower-extremity ulcer patients for longer, and they can refer the patient to a specialist if suspicion of a wrong first diagnosis arises. A 'wait and see' attitude can lead to devastating outcomes. 


\section{REFERENCES}

1. Franks P, Barker J, Collier M,Gethin G, Haesler E, Jawien, et al. EWMA document; Management of patients with venous leg ulcer: Challenges and current best practice. Journal of Wound Care 2016; (25), Suppl, 1-67.

2. Rice JB, Desai U, Cummings AK, Birnbaum HG, Skornicki M, Parsons N. Burden of venous leg ulcers in the United States. J Med Econ 2014; 17 (5):34756.

3. Phillips CJ, Humphreys I, Fletcher J, Harding K, Chamberlain G, Macey S. Estimating the costs associated with the management of patients with chronic wounds using linked routine data. Int Wound J 2015; doi:10.1111/iwj.12443.

4. Lindholm C, Searle R. Wound management for the 21 st century: Combining effectiviness and efficiency. Int Wound J 2016; (13):5-15.

5. Platsidaki E, Kouris A, Christodoulou C. Psychosocial aspects in patients with chronic leg ulcers. Wounds 2017; 29(10):306-310

6. Alavi A, Sibbald G, Phillips TJ, Miller F, Margolis DJ, Marston W, et al. What's new: Management of venou leg ulcers. J Am Acad Dermatol 2016; (74):627-40.

7. Mooij MC, Huisman LC. Chronic leg ulcer: Does a patient always get a correct diagnosis and adequate treatment? Phlebology 2016; (13):68-73.

8. Singer AJ, Tassiopoulos A, Kirsner RS. Evaluation and management of lower-extremity ulcers. N Engl J Med 2017; (169):1559-1567.

9. Kirsner RS, Vivas AC. Lower-extremity ulcers: Diagnosi and management. Brit J Dermatol 2015; (173):379-390 .

10. O Donnell TF, Passman MA, Marston WA, Ennis WJ, Dalsing M, Kistner RL,et al. Management of venous leg ulcers: Clinical practice guidelines of the Society leg ulcers: Clinical practice guidelines of the Society
for Vascular Surgery and the Americal Venous Forum. J Vasc Surg 2014; (60):3S-59S.

11. Isoherranen $\mathrm{K}$, Jordan $\mathrm{O}^{`}$ Brien J, Barker J, Dissemond J, Hafner J, Jemec BE, et al. EWMA Document; Atypical wounds: Best clinical practices and challenges. J Wound care 2019 Jun 1;28(Sup6):S1S92.

12. Hoffman MD. Atypical ulcers. Dermatol Ther 2013; (26):222-235.

13.Snyder RJ, Jensen J, Applewhite AJ, Couch K, Joseph WS, Lantis Ii JC, et al. A standardized approach to evaluating lower extremity chronic wounds using a checklist. Wounds 2019; 31:S29-S44.
14. Crawford F, Welch K, Andras A, Chappell FM. Ankle brachial index for the diagnosis of lower limb peripheral arterial disease. Cochrane Database Syst Rev. 2016; 9:CD010680. https://doi. org $/ 10.2174 / 157340308784245810$

15. Rajabi-Estarabi A, Kayssi A, Alavi A, Kirsner RS. Vascular tests for dermatologists. Am J Clin Dermato 2019. https//doi.org./10.1007/s40257-019-00441-x

16. Gao W, Chen D, Ran X. Malignant melanoma misdiagnosed as diabetic foot ulcer. Medicine 2017; (96):29.

17. Torrence G, Wrobel JS. A case of mistaken identity: Classic Kaposi sarcoma misdiagnosed as a diabetic foot ulcer in an atypical patient. Clin Diabetes Endocr 2019; (5):8.

18. Schultz G, Mozingo D, Romanelli M, Claxton K Wound healing and TIME; New concepts and scientific applications. Wound Repair and Regeneration 2005; (13):S1-S11.

19. Mavrogenis AF, Megaloikonomos PD, Antoniadou T, Igoumenou V, Panagopolus GN, Dimopoulos L, et al Current concepts for the evaluation and management of diabetic foot ulcers. Efort Open Reviews 2018; (3):513-525.

20. Ratchford EV, Evans NS. Approach to lower extremity edema. Curr Treat Options Cardio Med 2017; (19): 16 .

21. Hafner J, Ramelet AA, Schmeller W, Brunner UV. Management of venous leg ulcers. Current Probl Dermatol 1999; (27):4-7.

22. Hedayati N, Carson JG, Chi Y-W, Link D. Management of mixed arterial venous lower extremity ulceration: A review. Vascular Medicine 2015; 20(5):479-486.

23. Reiber GE. The epidemiology of diabetic foot problems. Diabet Med 1996; 13(Suppl. 1):S6-11.14 S.

24. Prompers L, Huijberts M, Apelqvist J, Jude E, Piagges A, Bakker K, et al. High prevalence of ischaemia, infection and serious comorbidity in patients with diabetic foot disease in Europe. Baseline results from the Eurodiale study. Diabetologia 2007 Jan; 50(1):18-25.

25. Arosi I, Hiner G, Rajbhandari S. Pathogenesis and treatment of callus in the diabetic foot. Curr Diabetes Rev 2016; 12(3):179-183.
26. National Pressure Ulcer Advisory Panel, European Pressure Ulcer Advisory Panel and Pan Pacific Pressure Injury Alliance, Haesler E, editor. Prevention and treatment of pressure ulcers: Quick reference guide. Cambridge Media: Osborne Park, Western Australia; 2014. 27. Siddle HJ, Firth J, Waxman R, Nelson EA, Helliwell PS. A case series to describe the clinical characteristics of foot ulceration in patients with rheumatoid arthritis. Clin Rheumatol 2012; (3):541-545.

28. Sunderkötter CH, Zelger B, Chen KR, Requena L, Piette W, Carlson JA, et al. Nomenclature of cutaneous vasculitis: Dermatologic addendum to the 2012 Revised International Chapel Hill Consensus Conference Nomenclature of Vasculitides. Arthritis Rheumatol, 2018; (70) 171-184.

29. Zuo KJ, Fung E, Tredget EE, Lin AN. A systematic review of postsurgical pyoderma gangrenosum: Identification of risk factors and proposed management strategy. J Plast Reconstr Aesthet Surg 2015; 68(3):295-303. https://dx.doi.org/10.1016/j. bjps.2014.12.036.

30. Isoherranen K. Post-surgical pyoderma gangrenosum: A retrospective analysis of four clinical cases. EWMA Journal 2019; (20):37-40.

31. Hafner J, Nobbe S, Partsch H, Läuchli S, Mayer D, Amann-Vesti B, et al. Martorell hypertensive ischemic leg ulcer: A model of ischemic subcutaneous arteriolosclerosis. Arch Dermatol 2010; 146(9):961968. https://dx.doi.org/10.1001/archdermatol.2010.224

32. Nigwekar SU, Thadhani R, Brandenburg VM. Calciphylaxis. N Engl J Med 2018; 378(18):17041714. https://dx.doi.org/10.1056/NEJMra1505292

33. Combemale P, Combemale P, Debure C, Baudot N, Machet L, Aout M, et al. Malignancy and chronic leg ulcers: The value of systematic wound biopsies: A prospective, multicenter, cross-sectional study. Arch Dermatol 2012; 148(6):704-708. https://dx.doi. org/10.1001/archdermatol.2011.3362

34. Minniti CP, Kato GJ. Critical reviews: How we treat sickle cell patients with leg ulcers. Am J Hematol 2016; 91(1): 22-30.

35. Conde Montero E, Sánchez-Albisua B, Guisado S, Angeles-Martin-Diaz M, Balbin-Carrero E, Valdivelsoramos M, de la Cueva Dobao P. Factitious ulcer misdiagnosed as pyoderma gangrenosum. Wounds 2016; 28(2):63-67. 